\title{
REPAIR CONNECTION WITH WOODEN WEDGED DOWELS: PRELIMINARY EXPERIMENTAL LABORATORY TESTS AND FEM MODEL FOR THE DESCRIPTION OF THE MECHANICAL BEHAVIOR
}

\author{
E. PERRIA ${ }^{1 *}$, S. SIEGERT ${ }^{2}$, X. LI ${ }^{1}$ AND M. SIEDER ${ }^{1}$ \\ ${ }^{1}$ Institute of Building Construction and Timber Structures, Technische Universität Braunschweig \\ Schleinitzstraße 21 A, D-38106 Braunschweig \\ e-mail: e.perria@tu-braunschweig.de - www.tu-braunschweig.de/ibholz (*corresponding author) \\ e-mail: xinyi.li@tu-braunschweig.de -www.tu-braunschweig.de/ibholz \\ e-mail: m.sieder@tu-braunschweig.de -www.tu-braunschweig.de/ibholz \\ 2 IGP Gockel PartGmbB - Ingenieure und Architektin, Kieler Straße 1, 34225 Baunatal \\ e-mail: siegert.svenja@gockel-ingenieure.de -www.gockel-ingenieure.de
}

Keywords: Preservation of monuments, timber, repair techniques, mechanical fasteners, laboratory testing, numerical modeling.

\begin{abstract}
The present paper describes the first steps of the research project by the title "Repair connection with wooden wedged dowels. New and alternative repair method that meets the demands of Monument Protection of built substance's gentle care and material fairness". The project aims to develop guidelines for static-constructive use of wood-wood repair connections with wooden wedged dowels.

In the research project, the first steps for the description of the mechanical model for the wooden wedged dowels have been approached. Literature about wooden pegs and dowels and built examples of wooden wedged dowels in existing buildings have been analyzed; more, preliminary laboratory tests and FEM simulations have been implemented.

In this paper, the results of the preliminary laboratory tests and the parallel development of a FEM model with the aim of describing the deformation behavior of the wooden wedged dowels for the most used wooden species will be presented. The main aims are: a) Analysis of the distribution of the strains / deformations in the dowel and in the connected building components when inserting the wedge. b) Analysis of the risk of opening of cracks in the materials. c) Analysis of distribution of stresses in the dowel and in the connected building elements utilizing FEM modeling calibrated on the experimental results.

Thanks to the evaluation of deformation behavior in the proposed geometrical configuration and material combinations of wedge, dowel and connected building elements, it has been possible to understand the general framework of deformation behavior and failure modes for different combinations of timber density of the connection components.
\end{abstract}

\section{INTRODUCTION}

The ICOMOS Charter of Mexico [1] - worldwide referenced document for the conservation of timber architectural heritage - explicitly asserts that the intervention on traditional and 
heritage timber structures must follow traditional carpentry techniques or compatible modern materials and techniques. The prioritization of traditional wood-wood connections aims to protect the material authenticity and integrity of the building and to guarantee the principles of reversibility and minimum intervention. In the Charter it is also specified that the new members or parts of members should aesthetically resemble the whole, but at the same time may be discreetly differenced from the original construction material, so that they can be identified at a later date.

On one side, hand-carved wooden nails based on historic examples continue to be used to secure the position of the half-timbered joints in one-to-one replacement of historical connections. On the other side, the situation is different when it comes to replacing damaged timbers, where historically no connection was in place. In these cases metal fasteners are used very often, especially if the repair has to be designed for tensile-stressed structural elements or if a clamping effect is required. In these load-cases, predestined solutions for strengthening measures are based on the use of metallic nails, screws and bolts, mainly for shear and tensile stressed wood joints, or of steel or plastic rods. In these cases, the choice of the metallic mechanical fasteners is almost unique, while the structural engineers cannot provide proof of the repair for alternative techniques or mechanical fasteners because there is no basis for calculation. However, these latter fastening techniques are not to be favored from the point of view of monument preservation's principles $[1,2]$ for the conservation of wooden built heritage.

The aim of the project is the development of technical knowledge for the repair connection with wooden wedged dowels, alternative wodden meehanical fasteners for historical timber
structures. The specific aim of the project is to develop a guideline for the static-constructive
use of wooden wedged dowels, which will allow the appropriate retrofitting or upgrading in line
with the requirements of monument protection.

2 BASIC PRINCIPLES: STATE OF THE ART AND REQUIREMENT MATRIX

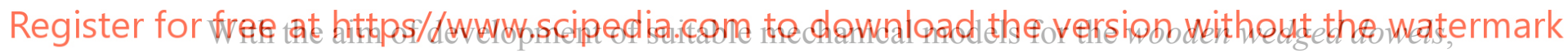

existing mechanical models and evaluation of load-bearing capacity for classical wooden nails and dowels were analyzed; furthermore, selected existing built examples of wooden wedged dowels were analyzed. For the analysis and evaluation of the wooden wedged dowels, which can be found in built examples, experienced carpenters, who have been using repair connections with wooden wedged dowels for decades, were asked about their properties, parameters for manufacturing and construction (empirical values).

Extrapolating pieces of information from literature and built references, the most significant parameters for the construction of a mechanical model for the wooden wedged dowels were collected in a requirement matrix; furthermore, it was identified which parameters could be fixed and which ones could make a significant contribution to a constructive evaluation.

Further boundary conditions were fixed basing on results of preliminary tests (TV).

\subsection{State of the art}

The majority of existing mechanical models are based on the analysis of historical dowelshaped wooden fasteners, mainly wooden pegs. The function of such fasteners was to secure the position of the half-timbered joint (withdrawal) and absorb tensile forces perpendicular to 
the fastener's axis. The development of dowel-shaped fasteners according to [3] and [4] starts from the $10^{\text {th }}$ century onwards with the development of wooden keys, wedges, pegs, pins, nails, trenails, head nails, up to dowels and plugs developed in the 19th century. Dowel-shaped wooden fasteners differ for shape in the sense of longitudinal development (slight tapered or cylindrical) and geometric adaptation of the cross section in the peg hole diameter (quadrangular, octagonal or round with or without nail head). Nowadays dowel-shaped fasteners are roughly divided into two categories: "wooden nails" for fasteners with octagonal cross-sections and "dowels" for ones with round cross-sections. On the subject "wooden nails" there are many publications $[5,6,7,8,9,10,11,12]$, which refer to the assessment of the loadbearing capacity of wooden pegs, pins, nails in the historical connection. In his research report, Müller [13] summarized the results of Ehlbeck, Hättich, Kessel, Augustin, Görlacher, Blaas, Ernst, Werner [5-12]. Furthermore, European Standards [14] and [15], provide further design proposals and load-carrying capacity for some kind of dowel-shaped wooden fasteners.

From the résumé of the state of the art, it is important to conclude that some mechanical models for dowel-shaped wooden fasteners are valid for specified boundary conditions (minimum spacing, minimum thickness, and fixed diameter or timber species) for connections in single or double-shear. The existing, most complete and flexible mechanical model, suitable for the adaptation for the wooden wedged dowels, is the one proposed in [15] based on the approach of [6]. On the basis of preliminary tests, the mentioned model will be implemented with relevant parameters and made suitable for the verification of repair connections with

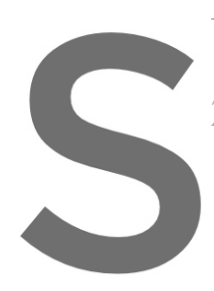
wooden wedged dowels

\subsection{Defined parameters for the}
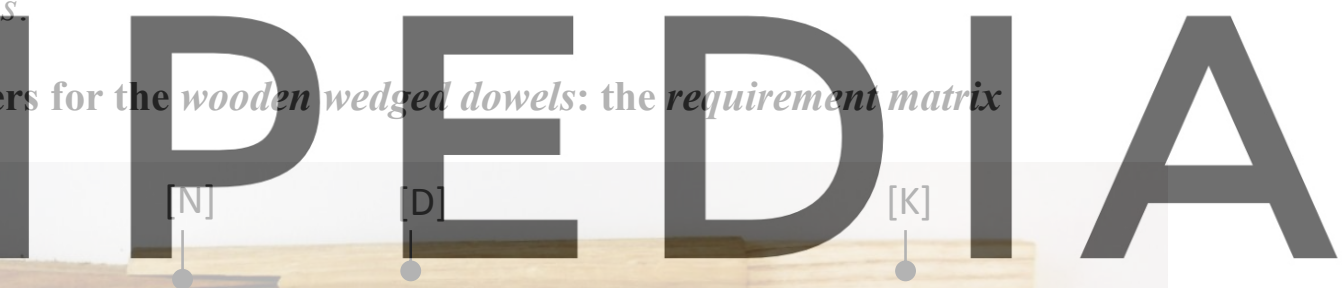

Register for free at https//www.scipedia.com to download the version without the watermark

Figure 1: Abbreviations for the parameters in the wooden wedged dowels

From the analysis of existing mechanical models and existing built examples of connections with wooden wedged dowels, some basis parameters were defined. The representation of following described parameters is also depicted in Figure 1 and Figure 2.

\section{DOWEL [D]:}

- Wooden species: European ash (Fraxinus excelsior, L.) (kiln-dried); European oak (Quercus sp.) (kiln-dried).

- Direction of the fibers: longitudinal direction of the fibers = length of the dowel.

- Length of the dowel $\left[l_{D}\right]$ : Variable, equal to the height of building components' cross section $\left[l_{D}=h_{B}\right]$.

\section{GROOVE [N]:}

- Diameter of the dowel $\left[d_{D}\right]: d_{D}=16-20-24-30 \mathrm{~mm}$

- Centered on the diameter of the dowel

- Length of the groove on Side $1(\mathrm{~S} 1)\left[\mathrm{l}_{\mathrm{N}, 1}\right]$ and groove on the Side $2(\mathrm{~S} 2)\left[\mathrm{l}_{\mathrm{N}, 2}\right]$ : each max. $\mathrm{l}_{\mathrm{N}} \leq 1 / 4 \cdot \mathrm{l}_{\mathrm{D}}$ and $\mathrm{l}_{\mathrm{N}, 1}=\mathrm{l}_{\mathrm{N}, 2}$ 
- Thickness of the groove $\left[t_{N}\right]: t_{N}=1-3 \mathrm{~mm}$ (according to production rule: $t_{N}=1 / 10 \cdot d_{D}$ )

- Length of dowel's core $\left[l_{D, \text { kern }}\right]: l_{D, \text { kern }}=l_{D}-l_{\mathrm{N}, 1}-\mathrm{l}_{\mathrm{N}, 2}$

- Distance between groove's bottom and shear line $\left[l_{k e r n, D} / 2\right]$

- Angle $\theta$ (parameter T1 in Table 1) between orientation of the groove and direction of annual rings on dowel's cross section: Fixed combination: $=T 1=0$. According to $[16$, $17,18]$ the maximum strength between tangential and radial is - at least for Quercus sp. - along the radial direction, because of the presence of medullary rays.

- Angle $\varphi$ (parameter T2 in Table 1) between the orientation of the groove on S1 [N,1] and fibers' direction in the building component: Variable orientation for different building component's wooden species.

$\rightarrow$ Variable probed in preliminary tests TV1.

- Angle $\beta$ (parameter $\mathrm{G}$ in Table 1) between the orientation of the groove on Side 1 [N,1] and groove on Side 2 [N,2]: Fixed combination: $\beta=\mathrm{G} 1=0$.

$\rightarrow$ Variable probed in preliminary tests TV1.

\section{WEDGE [K]:}

Wooden species of the wedge: Oak (Quercus sp.) (kiln-dried).

Direction of the fibers: longitudinal direction of the fibers $=$ length of the wedge.

Length of the wedge $\left[l_{K}\right]$ : fixed: $l_{K}=l_{N}+10 \mathrm{~mm}$

Width of the wedge $\left[b_{K}\right]: b_{K}=d_{D}$

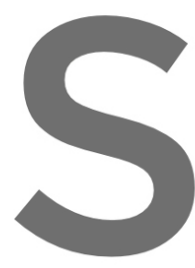

Thickness of the wedge (correspondent to dowel's

Thickness of th

$t_{K, 1} \cong 0 m m$

Angles in the wectoctical

Practical manufact

wedge, the width is up to 2 mm".

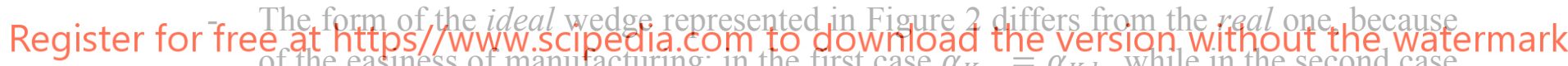

$\alpha_{K, a} \neq \alpha_{K, b}$, and $\alpha_{K, a}=90^{\circ}$

\section{BUILDING COMPONENTS [B]:}

- Connection only in single shear

- Wooden species of repair building component (must be same or similar to the in-situ timber, which bulk density \& moisture content have to be proofed):

- Hardwood: Oak (Quercus sp.) or similar density, minimum 5 year air-dried;

- Softwood: Spruce (Picea abies), silver fir (Abies alba), European redwood (Pinus sylvestris) or similar density, can be kiln-dried.

- Timber moisture content ideally constant: hypothetically fixed at: $u \cong 12-13 \%$

- Minimum width of the building component $\left[b_{B, \min }\right]: b_{B, \min }=120 \mathrm{~mm}$ equivalent to $1 \mathrm{x}$ row wooden wedged dowels $d_{D, \min }=20 \mathrm{~mm}$ with $a_{4, \min }=2,5 \cdot d_{D}$.

- Minimum height of the building components $\left[h_{B}\right]: h_{B, \min }=h_{B, 1}+h_{B, 2} \geq 120 \mathrm{~mm}$ i.e. connection in single shear with $h_{B, 1} \geq 60 \mathrm{~mm} \& h_{B, 2} \geq 60 \mathrm{~mm}$ equivalent to minimum length of dowel's core $\left[l_{D, \text { kern,min }}\right]: l_{D, \text { kern,min }}=60 \mathrm{~mm}$ 


\section{MINIMUM SPACING / DISTANCES IN THE CONNECTION:}

- Minimum distance to timber edges $\left[a_{4}\right]: a_{4, \min } \geq 2.5 \cdot d_{D}$

- Minimum distance to timber end $\left[a_{3}\right]: a_{3, \min } \geq 4 \cdot d_{D}$

- Minimum spacing among fasteners $\left[a_{1}=a_{2}\right]: a_{1}=a_{2} \geq 2 \cdot d_{D}$

- Minimum spacing between fasteners and checks (or cracks) in building components $\left[a_{r}\right]$ : $a_{r} \geq 2 \cdot d_{D}$.

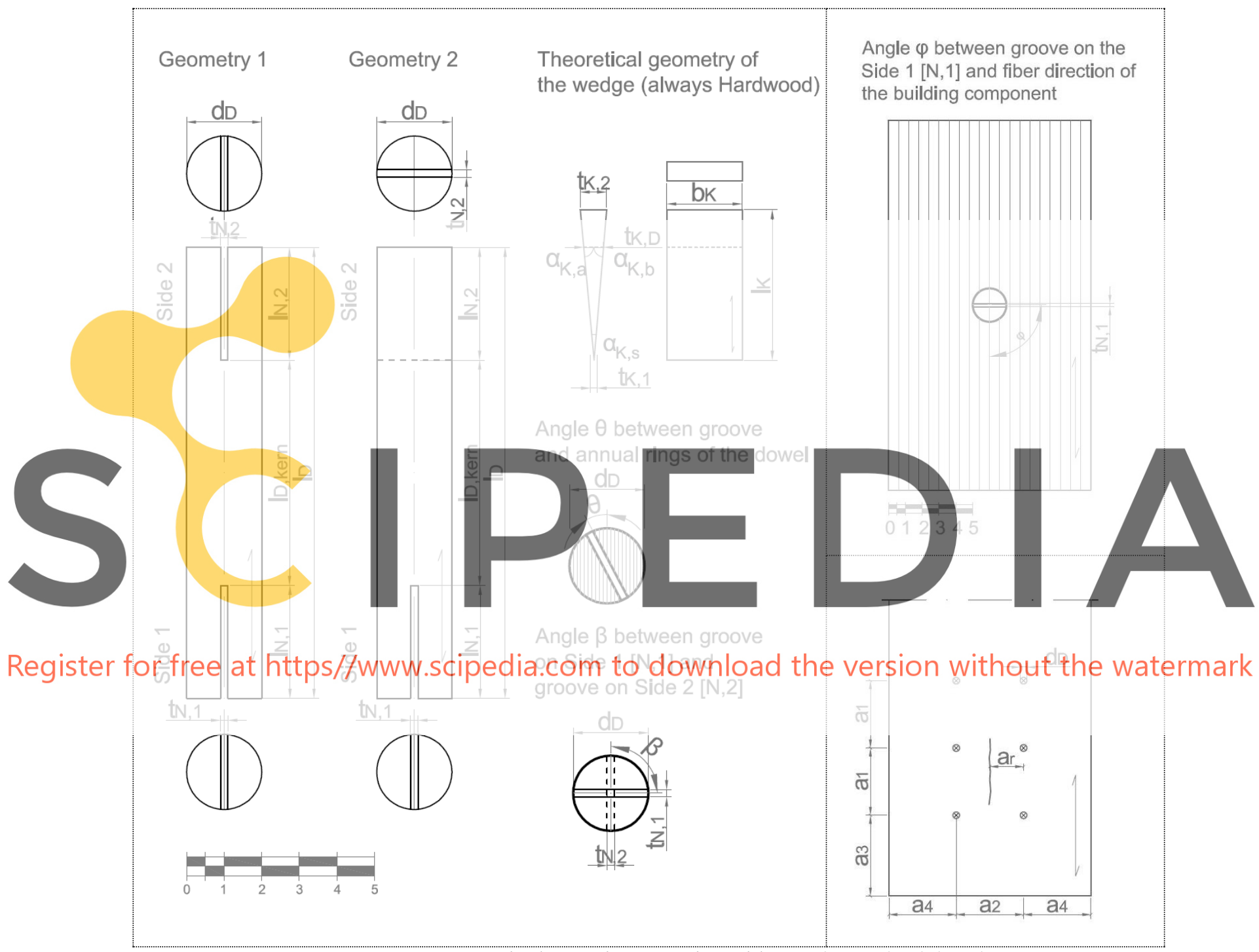

Figure 2: Parameters in the repair connection with wooden wedged dowels

\section{RESULTS OF EXPERIMENTAL PRELIMINARY INVESTIGATIONS}

In order to adapt the already existing models for „wooden nails“ and „dowels“ for the wooden wedged dowels, further important constructive and static parameters were analyzed in the preliminary experimental investigations (TV1) and afterwards implemented in the requirement matrix. 


\subsection{Aim}

Aim of TV1 was to determine some significant parameters that play a major role in the formation of cracks in the wooden wedged dowel and on components' surfaces and to bring forward the most favorable wood and geometrical combinations.

The initial parameters for the design of test specimens for the TV1 were fixed based on the empirical values and some relevant constructive parameters were considered as variables.

Specific aims of the preliminary tests TV1 were:

- Analysis of the distribution of strains in the dowel and in the building components as a consequence of introduction of the wedge in the groove;

- Analysis of cracks and failure modes in the materials;

- Fixing relevant parameters;

- Fixing relevant manufacturing rules;

- Collect data for the construction of a FE-Model

\subsection{Geometry of specimens}

\section{The geometry of test specimens for the TV1 was prepared according to the parameter defined}

in paragraph 2.2. Some specific parameters and variables for TV1 are listed below.

Fixed geometric parameters:

Dimension of building components: $(b \times h \times l) 120 \times(60+60) \times 220 \mathrm{~mm}^{3}$

Timber species: Dowel: oak; Building components: oak, spruce.

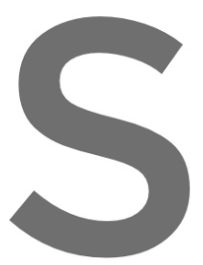

Dowel diameter:

Dowel length:

Thickness of the

Length of the groove: 1

Wedge parameters'
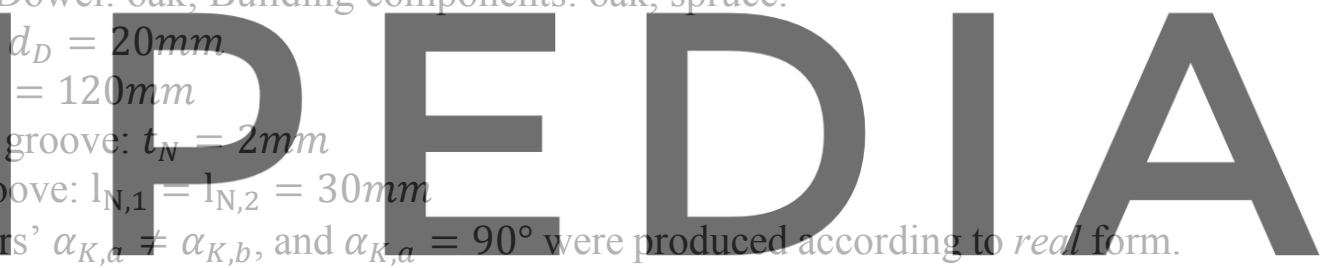

$\theta$ : angle between orientation of the groove with respect to the direction of annual rings


Variable geometric parameters:

The analyzed variables are described in detail in Table 1, and briefly listed below:

- H: Timber combinations:

- H1: Dowel: oak (HW) / Building component: spruce (SW)

- H2: Dowel: oak (HW) / Building component: oak (HW)

- T2: angle between orientations of the groove with respect to fiber direction of the building component on S1.

- G: angle between orientation of the groove on S1 and on S2. In the existing built examples the dowels were always rotated of $\beta=90^{\circ}$ to avoid the feared risk of dowel's core splitting. In the current research project, both the rotated $\left(\beta=90^{\circ}\right)$ and parallel $\left(\beta=0^{\circ}\right)$ arrangement of the groove are probed.

\subsection{Materials and methods}

The tests consist of the insertion of the wedge on both S1 and S2 by means of a universal testing machine with a strain-controlled test (velocity $=1 \mathrm{~mm} / \mathrm{s}$ ) (Figure 3$)$. The wedge was not introduced - as in real conditions - by means of a hammer. The reason is the attempt to 
repeat - for every specimen - the same boundary conditions: velocity, load amount, direction of the load (without natural direction's corrections of a human operator) and centered load on the wedge (in the real form: asymmetrical wedge).

Before the tests, the specimens were conditioned minimum $24 \mathrm{~h}$ in a climatic chamber $\mathrm{T}=20^{\circ} \mathrm{C}$ and $\mathrm{RH}=65 \%$.

Mechanical properties of the test specimens (bulk density, moisture content and bending E-module) were determined for both building components and dowels. Test specimens were divided into groups: specimen produced from the same original initial cross section belonged to the same group. The properties were determined using reference samples for each group.

The superficial visible and non-visible deformation/strain during the tests were recorded with the optical measurement system WM.

Test Steps:

- Step 0: In a first stage, the dowel is installed in the building component.

- In a second stage, the wedge is inserted in the dowel's groove as follows:

Step 1: introduction of the wedge in the groove up to the maximum depth of penetration (E.T.) equal to groove length. E.T.max,Step $1=30 \mathrm{~mm}=l_{N}$ );

Step 2: further introduction of the wedge up to a defined failure mode (buckling of wedge).

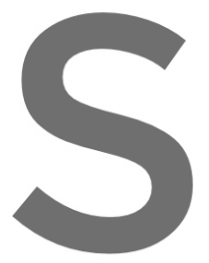

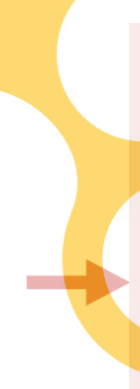

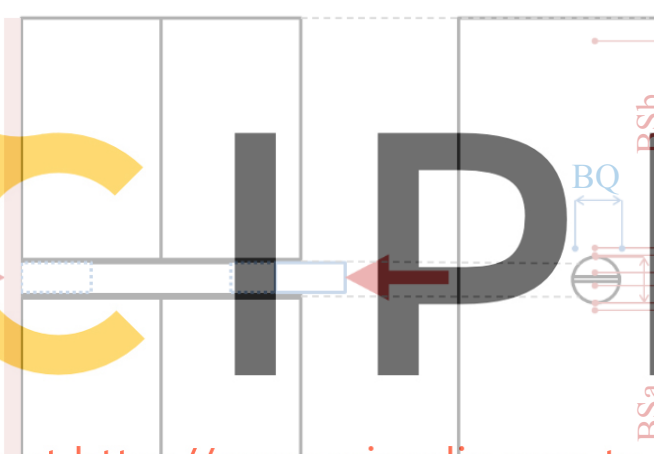

Register for free at https//www.scipedia.com to down

a)



Figure 3: Test setup and optical measurement system WM for measurement of deformation/strain: a) Scheme b) Picture

Table 1: Abbreviations for the variable parameters of the wooden wedged dowel in TV1

\begin{tabular}{|c|c|c|c|}
\hline $\begin{array}{c}\text { Timber } \\
\text { combinations }\end{array}$ & $\begin{array}{c}\text { Angle } \theta \text { between } \\
\text { orientation of the } \\
\text { groove and the } \\
\text { direction of the annual } \\
\text { rings on the dowel's } \\
\text { cross section }\end{array}$ & $\begin{array}{c}\text { Angle } \varphi \text { between the } \\
\text { orientation of the } \\
\text { groove on Side 1 } \\
\text { [N,1] and fibers' } \\
\text { direction in the } \\
\text { building component } \\
\text { on S1 }\end{array}$ & $\begin{array}{c}\text { Angle } \beta \text { between the orientation of } \\
\text { the groove on Side 1 [N,1] and } \\
\text { groove on Side 2 [N,2] }\end{array}$ \\
\hline $\mathrm{H} 1=\mathrm{SW}-\mathrm{HW}$ & $\begin{array}{c}\mathrm{T} 1-0 \rightarrow \theta=0^{\circ} \\
\mathrm{T} 1-45 \rightarrow \theta=45^{\circ} \\
\mathrm{T} 2=\mathrm{HW}-\mathrm{HW}\end{array}$ & $\begin{array}{c}\mathrm{T} 2-0 \rightarrow \varphi=0^{\circ} \\
\mathrm{T} 2-45 \rightarrow \varphi=45^{\circ} \\
\mathrm{T} 2-90 \rightarrow \varphi=90^{\circ}\end{array}$ & $\begin{array}{c}\mathrm{G} 1 \rightarrow \text { orientation of the groove on S2 } \\
\text { parallel to orientation on } \mathrm{S} 1 \\
\text { G2 } \rightarrow \text { orientation of the groove on S2 } \\
\text { perpendicular to orientation on S1 }\end{array}$ \\
\hline
\end{tabular}


Table 2: Tested geometric combinations and repetitions for timber combination

\begin{tabular}{|c|c|c|c|c|}
\hline \multirow{2}{*}{$\begin{array}{c}\text { Geometric } \\
\text { combinations }\end{array}$} & \multicolumn{2}{|c|}{ T2 on: } & \multicolumn{2}{|c|}{ Repetitions for timber combination } \\
\hline & $\mathrm{S} 1$ & $\mathrm{~S} 2$ & $\mathrm{H} 1$ & $\mathrm{H} 2$ \\
\hline T1-0_T2-0_G1 & $\varphi=0^{\circ}$ & $\varphi=0^{\circ}$ & 1 & 4 \\
\hline $\mathrm{T} 1-0 \mathrm{~T} 2-45 \mathrm{G} 1$ & $\varphi=45^{\circ}$ & $\varphi=45^{\circ}$ & 4 & 0 \\
\hline $\mathrm{T} 1-0 \mathrm{~T} 2-45 \mathrm{G} 2$ & $\varphi=45^{\circ}$ & $\varphi=135^{\circ}$ & 5 & 5 \\
\hline T1-0_T2-90_G1 & $\varphi=90^{\circ}$ & $\varphi=90^{\circ}$ & 5 & 5 \\
\hline $\mathrm{T} 1-0 \mathrm{~T} 2-90 \mathrm{G} 2$ & $\varphi=90^{\circ}$ & $\varphi=0^{\circ}$ & 5 & 5 \\
\hline
\end{tabular}

\subsection{Conclusion}

After testing, some specimens showed presence of cracks in the dowel in correspondence of groove's bottom and/or on building components' surface(s). Furthermore, for some specimens the penetration of the wedge was registered beyond $E . T .=l_{N}$. Therefore, dowel's core length after tests $\left[l_{D, k e r n}^{\prime}\right]$ is to understand as the $l_{D, k e r n}$ minus crack and penetration length in the dowel after testing. The results of TV1 are following discussed for three cases "results for H1", "results for H2", "general conclusions", and resumed in Table 3.

\section{Results for H1:}

\section{T2-0 G1:}

Dowel's core length $l_{D, \text { kern }}^{\prime}$ average after testing is $l_{D, \text { kern,mean }}^{\prime}=30.00 \mathrm{~mm}$.

Occurrence of failure in dowel's core is $100 \%$. Occurrence of cracks on the building

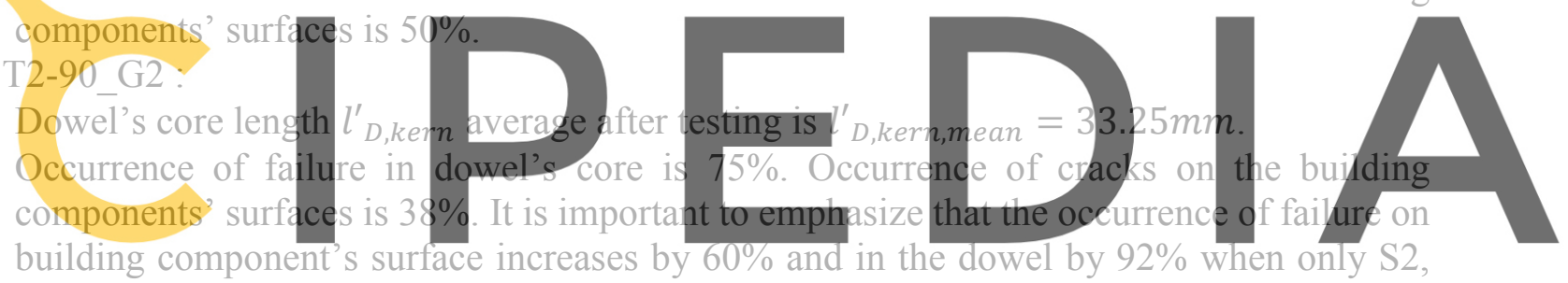

building component's surface increases by $60 \%$ and in the dowel by $92 \%$ when only $\mathrm{S} 2$,

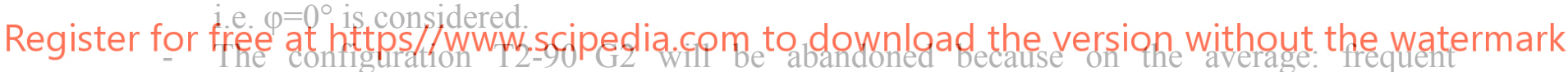
occurrence of failure (tension perpendicular to the grain) on building component's surface

S2 $\left(\varphi=0^{\circ}\right)$, and reduced dowel's core $l_{D, k e r n}^{\prime}$ (deep crack generation at S2 $\left(\varphi=0^{\circ}\right)$ ).

$\rightarrow$ In conclusion, all configurations with $\varphi=0^{\circ}$ will be abandoned for the timber combination H1 (T2-0_G1; T2-0_G2; T2-90_G2).

T2-45_G2:

- Dowel's core length $l_{D, k e r n}^{\prime}$ average after testing is $l_{D, \text { kern,mean }}^{\prime}=46.30 \mathrm{~mm}$.

- Occurrence of failure in dowel's core is $17 \%$. Occurrence of cracks on the building components' surfaces is $50 \%$.

T2-45_G1:

- Dowel's core length $l_{D, k e r n}^{\prime}$ average after testing is $l_{D, k e r n, m e a n}^{\prime}=60.00 \mathrm{~mm}$.

- Occurrence of failure in dowel's core is $0 \%$. Occurrence of cracks on the building components' surfaces is $13 \%$.

- Observation: higher bulk density induces on average smaller probability of opening of cracks in dowel's core: T2-45_G2: cracks in dowel's core: 6/12 - $\rho_{\text {DOLLE,mean }}=$ $0.560 \mathrm{~g} / \mathrm{cm}^{3}$; T2-45_G1: cracks in dowel's core: $0 / 16-\rho_{D O L L E, \text { mean }}=0.715 \mathrm{~g} / \mathrm{cm}^{3}$.

$\rightarrow$ In conclusion, the configuration T2-45_G1 will be kept for next investigations, the 
configuration T2-45_G2 will be abandoned.

T2-90_G1:

- Dowel's core length $l_{D, k e r n}^{\prime}$ average after testing is $l_{D, k e r n, \text { mean }}^{\prime}=60.00 \mathrm{~mm}$.

- Occurrence of failure in dowel's core is $70 \%$. Occurrence of cracks on the building components' surfaces is $0 \%$.

- Explanation: because of different E-moduli of the timber species in the connection, cracks occur in the dowel but not on the building component's surface. It is assumed that spruce has a higher elasticity and a higher capacity to absorb deformations compared to oak.

$\rightarrow$ In conclusion, the configuration T2-90_G1 will be kept for next investigations.

Results for $\mathrm{H} 2$ :

T2-0_G1:

- Dowel's core length $l_{D, k e r n}^{\prime}$ average after testing is $l_{D, k e r n, \text { mean }}^{\prime}=60.00 \mathrm{~mm}$.

- Occurrence of failure in dowel's core is $0 \%$. Occurrence of cracks on the building components' surfaces is $0 \%$.

T2-90_G2:

Dowel's core length $l_{D, \text { kern }}^{\prime}$ average after testing is $l_{D, \text { kern,mean }}^{\prime}=60.00 \mathrm{~mm}$.

Occurrence of failure in dowel's core is $19 \%$. Occurrence of cracks on the building components' surfaces is $33 \%$. It is important to emphasize that the occurrence of failure on building component's surface increases by $60 \%$ and in the dowel by $25 \%$, when only S2, i.e. $\varphi=0^{\circ}$ is considered.


$\mathrm{T} 2-45 \mathrm{G} 2$

Dowel's core length $l^{\prime}$, kern average after testing is $l^{\prime}$ kernmean $=46.30 \mathrm{~mm}$.

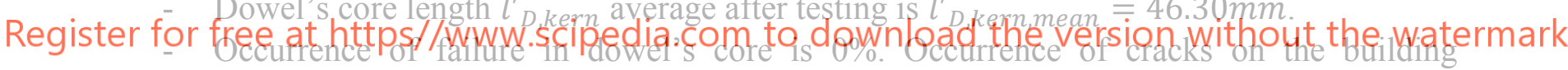
components' surfaces is $17 \%$

T2-45_G1

- Dowel's core length $l_{D, k e r n}^{\prime}$ average after testing is $l_{D, k e r n, \text { mean }}^{\prime}=60.00 \mathrm{~mm}$

- Occurrence of failure in dowel's core is $0 \%$. Occurrence of cracks on the building components' surfaces is $13 \%$.

- In the configuration T2-45 E.T.K,mean $=17.25 \mathrm{~mm}$ i.e. $t_{N}=b_{D}>2 \mathrm{~mm}$. Possible disadvantage: zero expansion of the dowel and no clamping-effect.

$\rightarrow$ In conclusion, the configuration T2-45_G1 will be kept for next investigations, the configuration T2-45_G2 will be abandoned.

T2-90_G1

- Dowel's core length $l_{D, k e r n}^{\prime}$ average after testing is $l_{D, k e r n, m e a n}^{\prime}=42.40 \mathrm{~mm}$.

- Occurrence of failure in dowel's core is $70 \%$. Occurrence of cracks on the building components' surfaces is $0 \%$.

- In the configuration T2-90 E.T.K,mean $=20.75 \mathrm{~mm}$ i.e. $t_{N}=b_{D}=2 \mathrm{~mm}$. Possible disadvantage: zero to low expansion of the dowel in T2-90 and no or low clamping-effect. $\rightarrow$ In conclusion, the configuration T2-90_G1 will be kept for next investigations. 
Table 3: Results of TV1 for timber and geometric combinations.

\begin{tabular}{|c|c|c|c|c|c|c|c|c|c|c|}
\hline & \multicolumn{5}{|c|}{$\mathrm{H} 1$} & \multicolumn{5}{|c|}{$\mathrm{H} 2$} \\
\hline & $\begin{array}{l}\vec{\Xi} \\
\dot{I}^{\prime} \\
\stackrel{1}{F}\end{array}$ & $\begin{array}{l}\overrightarrow{0} \\
\mathfrak{a}^{\prime} \\
\dot{\mathfrak{d}}\end{array}$ & 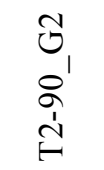 & 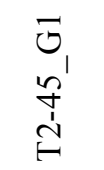 &  & $\begin{array}{l}\vec{\Xi} \\
\dot{I}^{\prime} \\
\stackrel{\sim}{ت}\end{array}$ & $\begin{array}{l}\vec{J} \\
\mathscr{a}^{\prime} \\
\dot{\vec{U}} \\
\vec{G}\end{array}$ & $\begin{array}{l}\mathcal{O} \\
\overbrace{}^{\prime} \\
\dot{1} \\
\tilde{F}\end{array}$ & 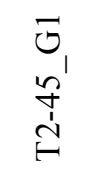 & 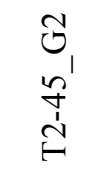 \\
\hline $\begin{array}{l}\boldsymbol{l}_{\boldsymbol{D}, \text { kern,mean }}^{\prime} \\
{[\mathrm{mm}]}\end{array}$ & 30.00 & 60.00 & 33.25 & 60.00 & 46.30 & 60.00 & 42.40 & 60.00 & 60.00 & 46.30 \\
\hline $\begin{array}{c}\text { Dowel's core failure } \\
{[\%]}\end{array}$ & 100 & 70 & 75 & 0 & 17 & 0 & 70 & 19 & 0 & 0 \\
\hline $\begin{array}{c}\text { Building components` } \\
\text { surfaces failure } \\
{[\%]}\end{array}$ & 50 & 0 & 38 & 13 & 50 & 0 & 0 & 33 & 13 & 17 \\
\hline
\end{tabular}

\section{General conclusions:}

Disadyantage of configuration G2: greater effort in manufacturing.

Advantage of configuration G1: less effort in manufacturing.

In correspondence with dowel's core presence of a torsional stress in G2 vs. no-torsional stress in G1 (later confirmed by FEM simulations)

Dowel's core remains sufficiently free of cracks independently from $\beta$.

$\Rightarrow$ In conclusion, the geometry G1 is preferred.

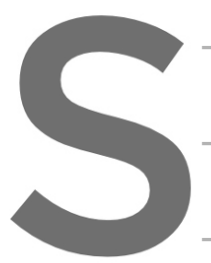

T2-90 higher stiffness parallel to the grain) T2-0 smaller stiffne parallel to the grain) Observation: during th


strength properties in tension
dge.
or strength properties in tension
edge.
quilding component (Step 0$)$, a deviation respect to the intended angle $\varphi$ is possible. Strength properties of HW are

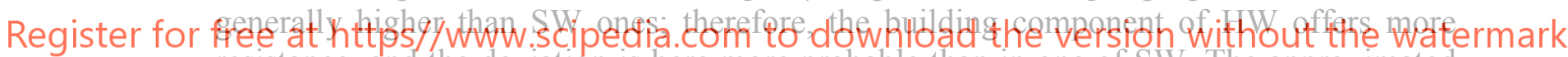
resistance, and the deviation is here more probable than in one of SW. The approximated deviation from the intended angle is $\varphi=\mp 45^{\circ}$.

\section{FEM SIMULATIONS}

The data collected during the TV1 were used for the development of a FE-Model of the repair connection with wooden wedged dowels. FE-simulations were performed with the software COMSOL.

\subsection{Aim}

The aim of the development of the FE-Model is to obtain a large number of virtual test results that realistically represent the stress / strain in different geometric and material configurations of the repair connection; therefore, a statistical evaluation of the parameters from the totality of the experimental and virtual results is possible. Specifically, in this first simulation series, the model was calibrated on the specimen H2_T1-0_T2-90_G1:d, and the presented results are a comparison between the results in the developed model and experimental results. 


\subsection{Geometry of the specimen}

The geometry of the model was chosen according to geometrical properties of the test specimens TV1 (see Paragraph 3.2). In the FE-Model the wedge has no correspondent geometrical element, but is simplified as a change in volume in the groove.

\subsection{Materials and Methods}

The actual material properties Young's modulus $\left(E_{m, 0}\right)$ and bulk density $(\rho)$ of the specimen H2_T1-0_T2-90_G1:d were determined. Unknown material properties for the specimen were assigned based on the experimentally ascertained $E_{m, 0}$. According to [16], timber strength class D35 was assigned to building components and D27 to the dowel. In the specimen there is a difference between actual and theoretical properties. The correlation between $E_{B, m, 0, E N 338}$ and $E_{B, m, 0, a c t u a l}$ is $96 \%$, while the correlation between $E_{D, m, 0, E N 338}$ and $E_{D, m, 0, a c t u a l}$ is $99.5 \%$. Furthermore, difference in density between components and dowel is according to [16] properties: $\Delta_{\rho}=40 \mathrm{Kg} / \mathrm{m}^{3}$; however, according to actual material properties, the difference in density is approx. $\Delta_{\rho}=100 \mathrm{Kg} / \mathrm{m}^{3}$. The linear elasto-plastic behavior of materials was assumed according to [17-19]. Based on bevor mentioned material properties, further unknowns in the material model $\left(E_{c, 0} ; E_{c, 90}\right.$; Poisson ratio) were determined by the iteration procedure FEM-updating. The material behavior of materials in the FE-Model was calibrated according to the optical measurement results for the test specimen H2_T1-0_T2-90_G1:d (See Figure 3 and Table 4) for following cases:

- (Piston) displacement / deformation perpendicular to the fibers (BQ) on building component's surface;

- (Piston) displacement / deformation parallel to the fibers (BS) on building component's surface;

- (Piston) displacement / deformation perpendicular to annual rings on dowel's cross section (D05).

Table 4: Displacement/ deformation diagrams in the specimen H2_T1-0_T2-90_G1d. Comparison between optical measurements and the results of the simulations.

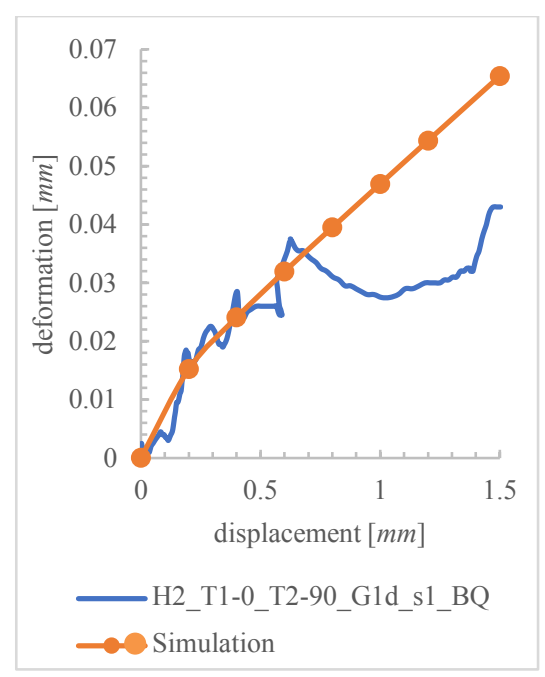

a)

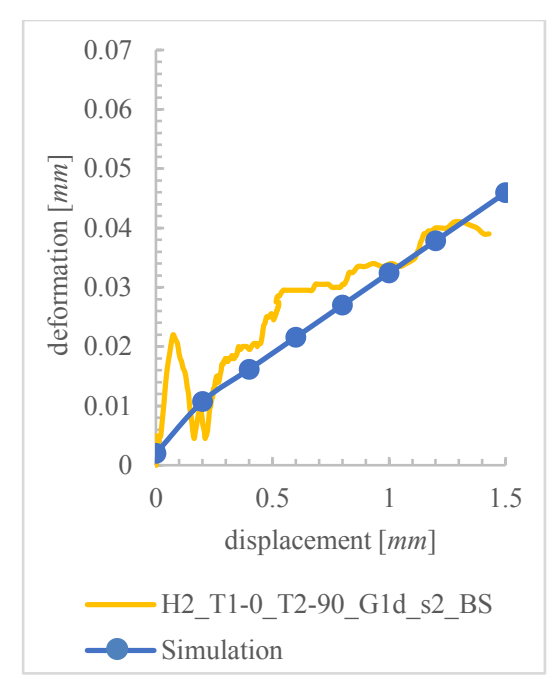

b)

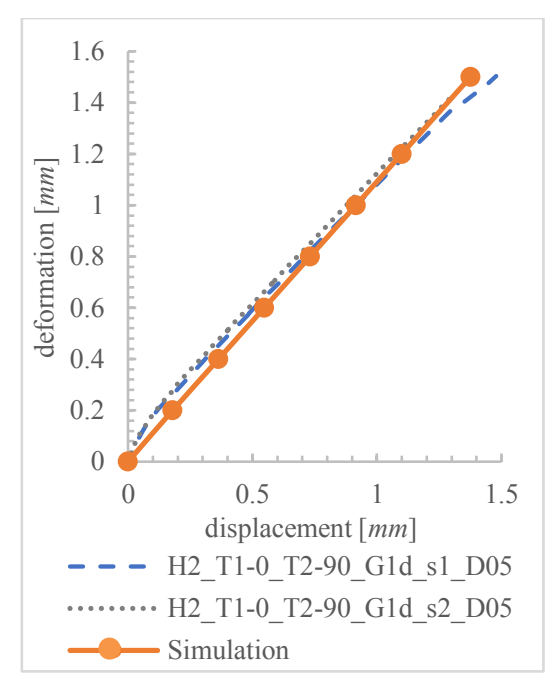

c) 
Table 5: Results of FE simulations for H2_T1-0_T2-90_G1 - Case study TV1.

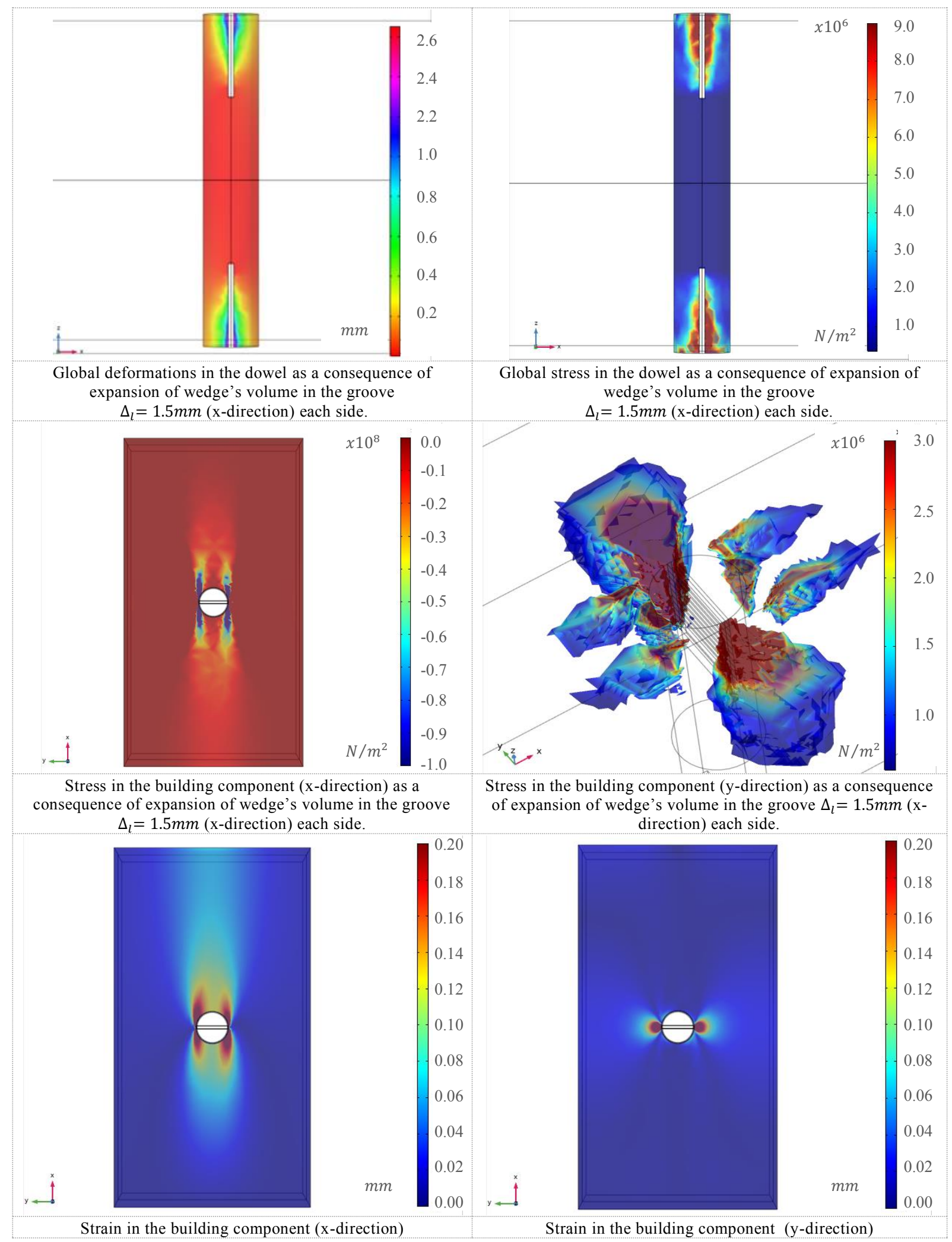


The simulations were performed under following assumptions: 1) The "action" in the experimental tests is the application of a load that permits through a displacement of the piston, the introduction of the wedge in the groove. In the FE-Model the introduction of the wedge is simulated as a change / shift in the volume of the groove. The maximum volume-change corresponds to the maximum (x-direction) displacement of the wedge in the performed test 2) The presence of friction and imperfections on the contact surface between wedge and dowel are neglected; 3) Radial and tangential material properties of the wood are the same.

\subsection{Conclusions}

Results of simulations for the geometry H2_T1-0_T2-90_G1:d are represented in Table 5. Here, distribution of stresses (exceeding $f_{t, 90}$ ) and deformations in the dowel and building component is depicted. The correspondence between simulations and experimental results is the best possible. Nevertheless, due to engineering assumptions in the material model, test results and simulations differ under some aspects: as soon as a crack occurs in the material, FEM results differ from the experimental ones because the idealized linear elasto-plastic behavior of the model (based on Navier theory) does not take into account the loss of energy after failure.

\section{CONCLUSIONS}

Results of experimental preliminary investigations TV1 permitted to identify the significant parameters that play a major role in formation of cracks in the wooden wedged dowel and on components' surfaces. Similarly, it was possible to compose the requirement matrix, which contains all determinant constructive and static parameters for the implementation of a numerical model for design of repair connections with wooden wedged dowels. Furthermore, results of experimental preliminary investigations permitted to identify the most favorable wood and geometrical combinations for the definition of the axial load-carrying capacity of wooden wedged dowels. This second step is already in process with the experimental preliminary investigations TV2. Furthermore, the results of the first FE-Model will be further implemented. In the second update of the FE-model mechanical properties $E_{m, 0}, \rho, E_{c, 0}, E_{c, 90}$ for building components and dowels will be determined in laboratory conditions according to [20] for different timber species. Actual material properties, together with actual elasto-plastic behavior of structural components and dowel will be used for the generation of more, realistic results for different timber combinations.

Acknowledgements. The research was financed with funds from the research initiative Zukunft Bau of German Federal Institute for Research on Building, Urban Affairs and Spatial Development (BBSR, BMI) (SWD-10.08.18.7-18.16). Furthermore, the research project was both financially and scientifically supported by: Niedersächsisches Landesamt für Denkmalpflege; IGP Gockel PartGmbB - Ingenieure und Architektin; Werkstätten für Denkmalpflege GmbH Quedlinburg.

\section{REFERENCES}

[1] ICOMOS ISCARSAH (2017). Principles for the conservation of wooden built heritage Adopted by the 19th ICOMOS General Assembly, New Delhi, India, 15 December 2017.

[2] Petzet M. Grundsätze der Denkmalpflege 1. ICOMOS, Heft des Deutschen Nationalkomitees, Bd. X, München (1992). 
[3] Gerner M. Entwicklung von Holzverbindungen Forschungs- und Untersuchungsergebnisse, Fraunhofer IRB Verlag, (2000).

[4] Ashurst, J. and N. English heritage. Practical building conservation. Timber. Ashgate, 2012.

[5] Blaas H.J., Ehlbeck J., Kreuzinger H., Steck G. Erläuterungen zu DIN 1052: 2004-08. Entwurf, Berechnung und Bemessung von Holzbauwerken. 2. Aufl. Deutsche Gesellschaft für Holzforschung. München und Karlsruhe: DGfH Innovations- und Service GmbH, Bruder, (2005).

[6] Blaas H.J., Ernst H., Werner H. Verbindungen mit Holzstiften - Untersuchungen über die Tragfähigkeit. In: Bauen mit Holz, 101, (1999), Heft 10, Pp. 45-52.

[7] Ehlbeck J., Hättich R. Tragfähigkeit und Verformungsverhalten von ein- und zweischnittig beanspruchten Holznägeln. In: Erhalten historisch bedeutsamer Bauwerke - Jahrbuch 1988, SFB 315, Universität Karlsruhe, Wilhelm Ernst \& Sohn Verlag für Architektur und Technische Wissenschaften, Berlin, (1989).

[8] Görlacher R. Empfehlungen für die Praxis. In: Historische Holztragwerke (Untersuchen, Berechnen und Instandsetzten), SFB 315, Universität Karslruhe, (1999).

[9] Holzer S. M. Statische Beurteilung historischer Tragwerke - Band 2 | Holzkonstruktionen. Ernst \& Sohn, (2015).

[10] Kessel M., Augustin R. Untersuchung der Tragfähigkeit von Holzverbindungen mit Holznägeln für Sanierung und Rekonstruktion von alter Bausubstanz.

Forschungsbericht, FH Hildesheim/Holzminden, Fachbereich Bauingenieurwesen, Labor für Holztechnik, Hildesheim, (1992).

[11] Kessel M., Augustin R. Untersuchung der Tragfähigkeit von Holzverbindungen mit Holznägeln. In: Bauen mit Holz, 96 (1994), Pp. 484-487.

[12] Gehri E. Holzbau- Tabellen Band 2. Lignum, Schweizerische Arbeitsgemeinschaft für das Holz, Zürich, (1990).

[13] Müller A., Vogel M, Lang S., Sauser F. Historische Holzverbindungen. Untersuchung des Trag- und Verformungsverhaltens von Historischen Holzverbindungen und Erstellung eines Leitfadens für die Baupraxis. Forschungsbericht der Fachhochschule Biel, Institut für Holzbau, Tragwerke und Architektur, (2016).

[14] DIN EN 1995-1-1 / NA: 2013-08 National Annex - Nationally determined parameters Eurocode 5: Design of timber structures - Part 1.1: General - Common rules and rules for buildings. Normenausschuss Bauwesen (NABau) im DIN, (August 2013).

[15] SIA 269/5:2011, Existing Structures - Timber Structures. Swiss Society of Engineers and Architects, Zurich, Switzerland.

[16] DIN EN 338:2016-07 Structural timber - Strength classes.

[17] Niemz P., Sonderegger W. Holzphysik. Physik des Holzes und der Holzwerkstoffe. Fachbuchverlag Leipzig im Carl Hanser Verlag, (2017). P. 275.

[18] Clorius, C. O., Damkilde, L., Hoffmeyer, P. Fatigue in Wood: An investigation in tension perpendicular to the grain. BYG-Rapport; No. R-038 Kgs. Lyngby, Denmark: Technical University of Denmark (DTU), (2001).

[19] Kollmann F. Technologie des Holzes und Holzwerkstoffe. Erster Band. Springer Verlag, (1951). Pp. 667-669.

[20] DIN EN 408:2012-10 Timber structures - Structural timber and glued laminated timber Determination of some physical and mechanical properties. 